\title{
Domestic Problems and Countermeasures of College Teachers Scientific Research Evaluation System
}

\author{
Xian Feng Hao And Wen Yan Tian \\ School of Economics And Management, North China Electric Power University, China \\ School of Economics And Management, North China Electric Power University,China \\ haofeng@ncepu.edu.cn,1369207031@qq.com
}

Keywords: College teachers;Scientific research evaluation; Scientific research evaluation system; Teachers' autonomy

\begin{abstract}
Objective:The policies, methods of research domestic college teachers scientific research evaluation and the current situation of evaluation subject, etc. Guarantee teachers' scientific research evaluation of scientific, objective and fair.Improve the enthusiasm of university teachers in the field of scientific research into and indirectly promote the healthy and orderly development of science and technology resources optimal allocation and scientific research work, thus increasing our country science and technology innovation ability and the comprehensive national strength.

Methods:Domestic and foreign policy analysis,Draw lessons from the successful experience of developed country university teachers' scientific research evaluation.

Results:In The Scientific evaluation mechanism, Scientific evaluation method of question And Evaluation of scientific research subject,There are many problems.Some measures must be taken to solve the problems.

Conclusion:Improve the domestic countermeasures of university teachers' scientific research evaluation system,Universities according to their own actual situation, draw lessons from the successful experience of developed country university teachers' scientific research evaluation, system reform step by step.

With the development of social economy and the rising of national education investment in scientific research, domestic colleges and universities as the cradle of national scientific research and education attaches great importance to by the society from all walks of life. In the field of scientific research, talent resources is particularly important, and teachers as excellent intellectuals have the professional academic accomplishment and keen thinking of scientific research, play an important role in the field. Improving teachers' scientific research level of the core is to do the assessment and evaluation of teachers' research.

After years of practice, the domestic colleges and universities teachers' scientific research evaluation system development, perfecting evaluation system, but now its scientific nature and rationality still need further specification and guarantee, many problems remain to be solved. In recent years, in view of the problems existing in the domestic university teachers' scientific research evaluation system, academic circles and government departments to increase the intensity of the investigation and study, from the aspects of university scientific research evaluation system analysis of the reasons for these problems, and puts forward some solving countermeasures.
\end{abstract}

\section{The analysis of the problems of university teachers' scientific research evaluation}

The problem of scientific evaluation mechanism, evaluation policy too much focus on results. Establish college teachers scientific research evaluation system suitable for China's national conditions of fundamental purpose is to stimulate the enthusiasm of teachers' participation in scientific research work, continuously improve the quality of scientific research, improve the comprehensive competitiveness of the school and school reputation. One-sided pursuit of scientific research achievement and the domestic many universities, overemphasis on the result of evaluation, 
assessment of the figures as a measure of value of scientific research standard lever, ignore the evaluation process and the quality of scientific research achievements, the evaluation policy can't rise to the correct guiding role.

The problem of scientific research evaluation methods, evaluation method and the process is not scientific and objective. Now lined in university, not to mention different college of education mode, focus is different, in the same school clear difference between various departments, various professional division of labor is clear, difference is very strong, research field and direction of each different, has its special differences, and evaluation is to adopt a model conformist, its limitation is obvious. In addition, different teachers ability is different, they are of different levels, in education and scientific research in such standard quantitative assessment method to measure each teacher's comprehensive quality makes the scientific nature and rationality of the compromised.

The problem of scientific research evaluation subject, teachers' participation is low, the lack of democracy. At present, the domestic university teachers' scientific research evaluation of the initiative or in a few hands such leadership in colleges and universities, teachers' participation is almost zero. This makes teachers often do not fully know evaluation standards and contents, blindly to scientific research results and research, work. Moreover, in the process of evaluation, teachers are dominant and does not supervise the evaluation makes them for evaluation of the results are reliable, easy to evaluators, easy to question the evaluation results, easily lead to vicious competition, make the school scientific research atmosphere.

To sum up, the current domestic evaluation system of university teachers' scientific research evaluation still existence question and the insufficiency, needs to further explore and perfect.

\section{The foreign teacher in university scientific research evaluation system}

The United States and Japan and other developed countries are mostly based on the evaluation of target management mode, this kind of evaluation is by no means a simple rewards and punishments, but pay more attention to the overall quality of teachers, the teachers' personal academic goals and development goals and management decision of the school together, not only can improve the quality of teacher education research, can help the development of the school. Existing in our country's higher education management system mode, the system of the colleges and universities to develop service for the educational goals, so are the distinctive features of teachers' scientific research evaluation system of higher education is to the organization's goals in the first place, this way really beneficial to school management, but also limits the teachers' development space.

Japan's evaluation, teacher evaluation is divided into education activities of scientific research activities or social activities, and campus management activities assessment of four parts, and these evaluation with quantitative evaluation and qualitative evaluation of two basic methods, a considerable degree of freedom for college teachers' work areas, objective, fair and scientific. In the process of teachers' scientific research evaluation, to give the teacher a considerable degree of freedom, the subjective evaluation and objective evaluation together, and to make public assessment of the teacher, pay attention to listen to the views of many aspects, so that we can effectively promote teachers enrich self, all aspects of development.

American colleges and universities is very strict, the assessment of teachers' academic ability mainly adopts the method of peer appraisal, teachers' self assessment and expert judgment independence to combine together, at the same time with external experts and professors of scientific identification of the evaluation results, the subjective evaluation and objective evaluation together, both to avoid the teacher's mistrust of the review results, on the other hand, improve the teachers' participation. 


\section{Improve the domestic countermeasures of university teachers' scientific research evaluation system}

According to the current problems of domestic university teachers' scientific research evaluation system, draw lessons from foreign successful experiences and practices, the author will perfect the domestic university teachers' scientific research evaluation system put forward the following Suggestions.

Improve the assessment mechanism of scientific research, pay more attention to the process and quality. Draw lessons from the United States, Japan and other developed countries of the target management method, the university teachers' scientific research evaluation and the development of the potential of the development strategy of the school, teachers and school management decision-making closely linked together, better realize the goal of education in the schools and countries. In addition, universities should truly standardize research results of the inspection process, strictly the quality pass, set up is given priority to with quality, both in the number of scientific research evaluation system; Note weakened by teachers' grading evaluation results, weakening teachers titles, bonuses, allowances and other real interest and teachers' scientific research evaluation results, overcome the amoral behavior of academic, purify academic competition atmosphere; To give university teachers' autonomy, improve teachers' scientific research enthusiasm, and not just by the scientific research evaluation results to improve the teachers' competitiveness.

Diverse scientific research evaluation methods, pay attention to the assessment content diversity. In view of the different development goals and direction in colleges and universities, a unified evaluation standard is no longer applicable, therefore in the process of university teachers' scientific research evaluation according to the school's own development direction and development needs for different evaluation standard and evaluation method. In addition, the same school different specialized special regularity makes colleges and universities for different professional classify different types of scientific research evaluation. In a certain way, make classified scientific research in university, teachers' scientific research goal is more explicit, improve the whole scientific research ability and level of colleges and universities. In addition, aiming at the problem of scientific research evaluation method is simple and quantitative, quantitative evaluation and qualitative evaluation of two basic methods, evaluation of different research projects adopt different methods, specific issues specific analysis, to prevent the "one size fits all".

Rich in colleges and universities evaluation main body, improve teachers' autonomy. Draw lessons from the practice of university teachers' scientific research evaluation, to establish and perfect the system of expert evaluation, the choice of experts in the process of research its academic level of scientific research ability, and social relations, guarantee the reliable of the evaluation results, the monopoly of the academic power to prevent. After the evaluation of the public in time, ensure the fair assessment. In addition, pay attention to the participation of the teachers in the process of evaluation, open and transparent, and not just small groups such as school leadership. Teachers to be involved in the research process will understand school evaluation policy, to avoid the blindness in the process of scientific research and undirected, this can be either to a certain extent, promote the evaluation result objective and fair, and gave the teacher autonomy.

Evaluators communication with teachers can give the space of teacher reflection, teachers constantly improve themselves, enrich their knowledge, improve the teaching scientific research level. In addition, by introducing social intermediary organizations in colleges and universities to strengthen the social participation, independent development of socialization of university teachers' scientific research evaluation institutions, can make the evaluation work of university's scientific research has more independence, the assessment results more objective and scientific evaluation. 
The domestic colleges and universities and the improvement of teachers' scientific research evaluation system is a system engineering, various universities according to their own actual situation, draw lessons from the successful experience of developed country university teachers' scientific research evaluation, system reform step by step, study the scientific, reasonable and effective system for scientific research performance, the completion of tasks of fair appraisal of scientific research quality, the scientific research and the actual benefit, in order to achieve the optimization of scientific research work, inspire teachers' scientific research enthusiasm, promote the scientific research level, to realize the sustainable development of our country education scientific research results.

\section{References}

[1].D.F. Cao. Theory of private colleges scientific research performance quantitative assessment system build, Chinese science and education innovation Tribune, 2014 (7) (In Chinese)

[2].Y.Q.Zhang. Domestic university teachers' evaluation of the existing problems and countermeasures research, Shandong youth, 2013 (5) (In Chinese)

[3].Y.F Wang, L.N. Jia . Comparative study on the evaluation of university's scientific research both at home and abroad, evaluation and management, 2005 (3) (In Chinese)

[4].Q.S.Zhu, R.Y. Ye, Chiang from the root. Thinking caused by college teachers scientific research evaluation in developed countries, China university of science and technology and industrialization, 2009 (12) (In Chinese)

[5].J.Wang. Present situation and countermeasures of university scientific research evaluation system, Hefei university of technology, 230009 (In Chinese)

[6].Z.T.Yang. Perfect the thinking of scientific research evaluation at colleges and universities, scientific and technological progress and countermeasures, 2013 (2) (In Chinese)

[7].W.Long. Our country university scientific research evaluation system analysis, Inner Mongolia science and technology and economy, 2011 (8) (In Chinese)

[8].J.S.Chen. The appraisal of scientific research in higher educational institutions and its countermeasure research, academic exploration, 2013 (8) (In Chinese)

[9].M.Z.Xu, Y.L.Wang, J.N.Fang. Thoughts and Suggestions to improve scientific research evaluation in colleges and universities, China university of science and technology, 2013 (8) (In Chinese)

[10].X.A.Zhang. Try to talk about the improvement and perfection of the evaluation work of university's scientific research, technology and innovation management, 2011 (6) (In Chinese) 